\title{
Caracterização de Solda de Revestimento de AWS 317L Depositados por GMAW Duplo Arame em Aços ASTM A 516 Gr 60 para Uso na Indústria do Petróleo
}

\author{
(Characterization of the AWS 317L Weld Overlay Applied by Twin Wire GMAW on ASTM A516 Gr 60 Steel Used in Oil and \\ Gas Industry)
}

\author{
Marcos Mesquita da Silval, Wellington Cordeiro Oliveiral, Theophilo Moura Maciel ${ }^{1}$, Marco Antonio dos Santos ${ }^{1}$, Marcelo Ferreira \\ Motta $^{2}$ \\ ${ }^{1}$ Universidade Federal de Campina Grande, Departamento de Engenharia Mecânica, Laboratório de Soldagem, Paraíba, Campina \\ Grande, theo@ufcg.edu.br \\ ${ }^{2}$ Universidade Federal do Ceará, Departamento de Engenharia Mecânica, Laboratório de Eng. e Soldagem
}

\begin{abstract}
Resumo
Este trabalho teve como objetivo avaliar as características microestruturais de revestimentos aplicados por soldagem utilizando-se o processo GMAW com duplo arame e o metal de adição AWS E317L sobre metal de base ASTM A 516 Gr 60. Durante as soldagens empregou-se dois níveis de energia de soldagem $(1170 \mathrm{~kJ} / \mathrm{m}$ e $1530 \mathrm{~kJ} / \mathrm{m})$, um gás de proteção correspondendo a uma mistura de argônio e oxigênio (95\% $\mathrm{Ar}$ e $5 \% \mathrm{O}_{2}$ ) e uma temperatura interpasse de $150^{\circ} \mathrm{C}$. Em seguida, as amostras foram caracterizadas utilizandose ensaios de microscopia ótica e microdureza. Os resultados obtidos indicaram um aumento na diluição e na extensão da zona termicamente afetada (ZTA) com o aumento da energia de soldagem. Além disso, também houve a formação de zonas parcialmente diluídas (ZPD) na interface revestimento/substrato, apresentando valores acima de 300HV. A quantidade de ZPD também foi maior para o nível de energia de soldagem mais elevado.
\end{abstract}

Palavras-chave: Revestimento, GMAW com duplo arame, AISI 317L, Zonas Parcialmente Diluídas

Abstract: The aim of this study was to evaluate the metallurgical characteristics of weld overlay applied by Twin Wire GMAW process and the AWS E317L filler metal on ASTM A 516 Gr 60 base metal. During welding it was employed two levels of heat input (H = $1170 \mathrm{~kJ} / \mathrm{m}$ and $\mathrm{H}=1530 \mathrm{~kJ} / \mathrm{m})$ and a mixture of argon and oxygen $\left(95 \% \mathrm{Ar}\right.$ and $\left.5 \% \mathrm{O}_{2}\right)$ as shielding gas. Besides, all welds were carried out without preheat, however, an interpass temperature of $150^{\circ} \mathrm{C}$ was used. Then, the specimens were characterized using optical microscopy and microhardness tests. The results showed an increase in dilution and heat affect zone extension when the heat input increases. Moreover, there was also the formation of partially diluted zones (PDZ) along the fusion line, presenting values above $300 H V$. The formation of PDZ was larger for the highest heat input level.

Keywords: Weld overlay, Twin wire GMAW, AISI 317L, Partially Diluted Zones

\section{1 - Introdução}

$\mathrm{O}$ conceito original de soldagem de aços dissimilares (SAD) se refere à união de dois sistemas de ligas diferentes, isto é, a união de dois metais de base (MB) de composições químicas significativamente diferentes - utilizando-se um metal de adição devidamente selecionado - resultando numa junta de aços dissimilares (JAD) [1, 2, 3]. Em geral, os MB a serem unidos são aços ferríticos e austeníticos e os metais de adição empregados são os aços inoxidáveis austeníticos ou ligas de Níquel.

Outro tipo de aplicação de SAD são os revestimentos metálicos depositados por soldagem em substratos menos nobres

(Recebido em 13/02/2010; Texto final em 24/08/2010). a fim de melhorar a resistência à corrosão destes substratos. De modo análogo às $\mathrm{JAD}$, geralmente os revestimentos são depositados através de soldagem ao arco elétrico com metais de adição de aços inoxidáveis austeníticos ou de ligas de Ni $[1,4]$. $\mathrm{Na}$ indústria petroquímica estes revestimentos metálicos podem ser aplicados em equipamentos submetidos a meios agressivos contendo sulfeto de hidrogênio tais como vasos de pressão, reatores, tubulações, entre outros [1,5,6]. Por exemplo, na indústria de petróleo e gás, é comum substratos de aço carbono serem revestidos com aço inoxidável por razões econômicas [7]. No entanto, uma das preocupações durante a soldagem de aço inoxidável austenítico em aços carbonos corresponde ao nível de diluição resultante das condições e processo de soldagem. Quanto menor a diluição, menor a probabilidade de formação de microestruturas frágeis e susceptíveis à corrosão[8]. Além disso, devido à grande diferença de composição química entre os aços inoxidáveis e carbono e às condições de soldagem, zonas parcialmente diluídas (ZPD) podem se formar ao longo da linha 
de fusão. Estas zonas podem apresentar dezenas de mícrons de largura, diversas morfologias (praia, península e ilhas) e composição química intermediária entre o $\mathrm{MB}$ e o metal de solda (MS), isto é, uma composição química de baixa liga (em geral, 3-5\% Cr e 2-3\% Ni) $[1,2,3,6]$.

A formação de ZPD é função tanto da composição química quanto das condições de soldagem. A manipulação do arco elétrico e as variações na turbulência da poça de fusão têm uma influência significativa na formação destas ZPD.

Em soldagens dissimilares, uma mistura completa na poça total da solda, incluindo a interface desta poça com MB sólido, é muito improvável. De acordo com a mecância dos fluidos, a velocidade de deslocamento de um líquido é zero sobre uma parede sólida (condição de contorno de não-deslizamento) [9]. Assim, próximo à interface da poça de fusão a convecção é enfraquecida, e uma camada líquida de MB estática ou de fluxo laminar pode existir na inteface $[10,11]$. E, durante a soldagem esta camada de MB líquido pode não se misturar ou misturarse parcialmente com o MS líquido da poça, gerando ZPD. A formação de uma praia é atribuída à existência desta camada, quando a mesma se solidifica sem se misturar com o MS líquido. Adicionalmente, a espessura da praia pode variar ao longo da interface revestimento/substrato, dependendo da variação da energia de soldagem e do gradiente de temperatura normal à interface da poça de fusão ao longo desta interface [10].

A formação de ZPD ocorre quando o MB líquido é impulsionado para dentro da poça de fusão através da convecção que age nesta poça. Esta situação ocorre se a temperatura líquidus do MS $\left(\mathrm{T}_{\mathrm{MS}}\right)$ for menor que a temperatura líquidus do $\mathrm{MB}$ $\left(\mathrm{T}_{\mathrm{MB}}\right)$. Por outro lado, com $\mathrm{T}_{\mathrm{MS}}>\mathrm{T}_{\mathrm{MB}}$, a convecção gerada pelo arco elétrico é capaz de empurrar o MS líquido para dentro da camada de MB líquido gerando intrusões e, consequentemente, formando penínsulas e ilhas de orientações aleatórias. Segundo a literatura, estas ZPD (praia, peninsulas e ilhas) são mais prováveis acontecer quando $\mathrm{T}_{\mathrm{MS}}>\mathrm{T}_{\mathrm{MB}}[10]$.

A dureza elevada observada nos contornos destas ZPD (praia, península e ilhas) está associada aos gradientes de composição química existentes ao longo da interface revestimento/substrato. Por sua vez, estes gradientes de composição química são atribuídos à mistura parcial entre os dois líquidos (MB e MS) e segregação de soluto durante a solidificação [10].

A literatura afirma que estas ZPD podem ser constituídas de martensita, precipitados e/ou fases intermetálicas tais como, Sigma e Chi [1]. Devido a estas características, as ZPD tornamse susceptíveis a ataques corrosivos por pitting, fragilização por hidrogênio, corrosão sob tensão podendo resultar em falhas na interface revestimento/substrato [1]. Portanto, torna-se necessário buscar condições de soldagem que minimizem ou até eliminem estas ZPD.

Assim, objetivo deste trabalho é avaliar as características microestruturais de revestimentos de aço AISI 317L depositados por soldagem em aço ASTM A 516 Gr 60, avaliando a influência da variação dos parâmetros de soldagem sobre a diluição e sobre a presença e morfologia de ZPD na interface revestimento/ sustrato.

\section{2 - Materiais e Métodos}

Neste trabalho a deposição dos revestimentos de aço AISI 317L em substratos de aço ASTM A516 Gr 60 foi realizada através do processo de soldagem GMAW com duplo arame. As composições químicas do revestimento e do substrato estão dispostas nas Tabelas 1 e 2 , respectivamente.

Tabela 1: Especificação de composição química do aço ASTM A516 Gr 60 .

\begin{tabular}{cccccc}
\hline & \multicolumn{5}{c}{ Composição (\% em peso) } \\
\cline { 2 - 6 } ASTM & $\mathrm{C}^{*}$ & $\mathrm{Mn}$ & $\mathrm{P}^{*}$ & $\mathrm{~S}$ & $\mathrm{Si}$ \\
\cline { 2 - 6 } A516 Gr 60 & 0,21 & $0,60-0,90$ & 0,035 & 0,035 & $0,15-0,40$ \\
\hline * Teores máximos aceitáveis. Fonte: ASTM (2004)[12]
\end{tabular}

* Teores máximos aceitáveis. Fonte: ASTM (2004) [12].

Tabela 2: Composição química nominal do metal de adição AWS E317L.

\begin{tabular}{ccccccc}
\hline \multirow{2}{*}{ Metal de adição } & \multicolumn{6}{c}{ Composição (\% em peso) } \\
\cline { 2 - 7 } & $\mathrm{C}$ & $\mathrm{Cr}$ & $\mathrm{Ni}$ & $\mathrm{Mo}$ & $\mathrm{Mn}$ & $\mathrm{Si}$ \\
\hline E317L & 0,03 & 18,50 & 13,00 & 3,80 & 1,00 & 0,70 \\
\hline
\end{tabular}

Fonte: Böhler (2008) [13].

Já na Tabela 3 têm-se os principais parâmetros de soldagem adotados durante a aplicação dos revestimentos. Estes revestimentos foram executados no Laboratório de Engenharia de Soldagem (ENGESOLDA) na Universidade Federal do Ceará. Todas as soldagens foram realizadas sem pré-aquecimento. Entretanto, foi mantida uma temperatura de interpasse de $150^{\circ} \mathrm{C}$. Estas soldagens foram realizadas através de um robô industrial e, como gás de proteção, foi empregada uma mistura de $95 \%$ de argônio e $5 \%$ de $\mathrm{O}_{2}$. Os revestimentos foram aplicados em substratos cuja geometria e principais dimensões estão indicadas na Figura 1a. O comprimento do substrato foi de $160 \mathrm{~mm}$.

Tabela 3: Parâmetros de Soldagem utilizados.

\begin{tabular}{cccc}
\hline Ensaios & $\mathrm{I}(\mathrm{A})$ & $\mathrm{V}_{\mathrm{S}}(\mathrm{m} / \mathrm{min})$ & Energia $(\mathrm{kJ} / \mathrm{m})$ \\
\hline 1 & 170 & 0,40 & 1530 \\
2 & 130 & 0,40 & 1170 \\
3 & 170 & 0,52 & 1170 \\
\hline
\end{tabular}

Após o revestimento dos substratos realizaram-se análises metalográficas-noLaboratório de Metalografia do Departamento de Engenharia Mecânica da Universidade Federal de Campina Grande (DEM/UFCG) - através de técnicas convencionais (corte, lixamento, polimento, ataque químico e documentação de microestruturas), em espécimes de cada ensaio de soldagem. Nestas análises empregou-se o reagente químico nital (1,5\%). 


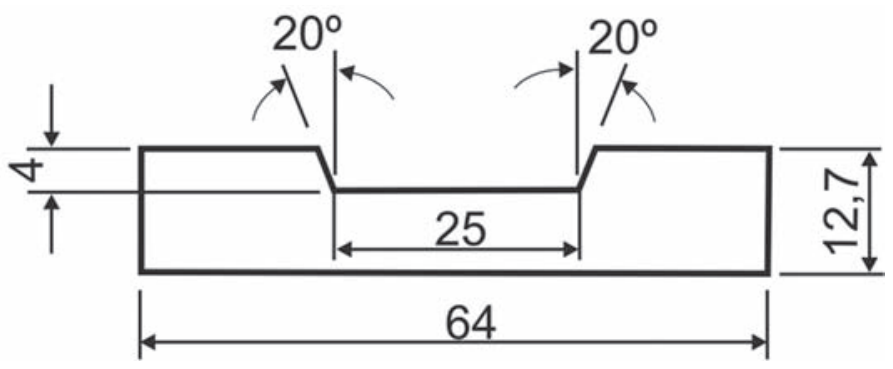

(a)

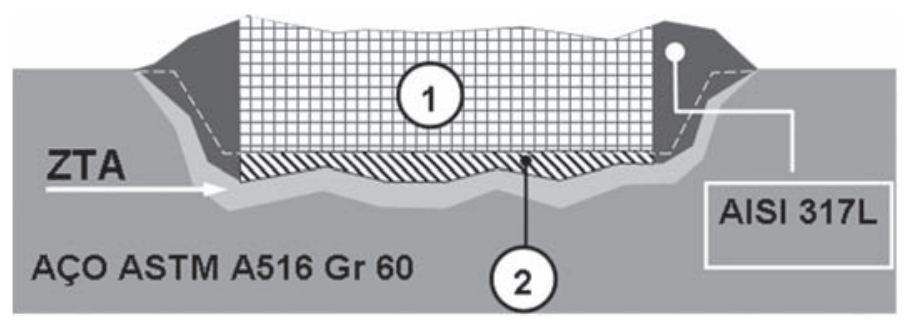

(b)

Figura 1 - (a) Principais dimensões do substrato (em mm), (b) identificação das regiões para o cálculo das diluiçõos.

Após os ensaios metalográficos, foram calculadas as diluições para cada ensaio de soldagem. As medições das áreas (1) e (2) (Figura 1b) foram realizadas no aplicativo Autocad ̂̂. Assim, a diluição foi definida conforme a equação abaixo,

Diluição(\%)=[área(2)/(área (1)+ área)(2)]x100\%

As diluições laterais do metal de solda (Figura1b) não participaram da Equação (1), já que em situações reais estas áreas não estariam presentes. Já os ensaios de microdureza foram executados de acordo com duas metodologias. Na primeira as impressões foram feitas ao longo de seis linhas verticais (Figura 2a), adotando-se uma carga de $0,3 \mathrm{~kg}$ por 15 segundos, com a intenção de observar o gradiente de dureza ao longo das regiões MS, ZTA e MB. A distância entre impressões no MS foi de $0,5 \mathrm{~mm}$, enquanto que na ZTA e no MB esta distância foi de $0,25 \mathrm{~mm}$. Já na segunda metodologia as impressões foram realizadas adjacentes à linha de fusão pelo lado do MS (Figura 2b). Para isso, utilizou-se uma carga de $0,1 \mathrm{~kg}$ por $15 \mathrm{~s}$ em cada impressão. A carga foi reduzida para $0,1 \mathrm{~kg}$ a fim de que os tamanhos das impressões não fossem maiores do que as ZPD. Nesta metodologia, a distância entre impressões foi de $0,25 \mathrm{~mm}$. Quanto à extensão da ZTA $\left(\mathrm{E}_{\mathrm{ZTA}}\right)$, a mesma foi medida conforme apresenta o detalhe da Figura 2b, tomando-se três medidas ao longo da seção e, portanto, obtendo-se uma média.

\section{3 - Resultados e Discussão}

Após a aplicação dos revestimentos, realizou-se a microscopia ótica das regiões resultantes desta aplicação. A Figura 3 apresenta a macrografia de uma seção transversal do corpo de prova (CP) revestido enquanto a Figura 4 exibe a micrografia do substrato de aço ASTM A516 Gr 60, apresentando uma microestrutura clássica de ferrita e perlita.

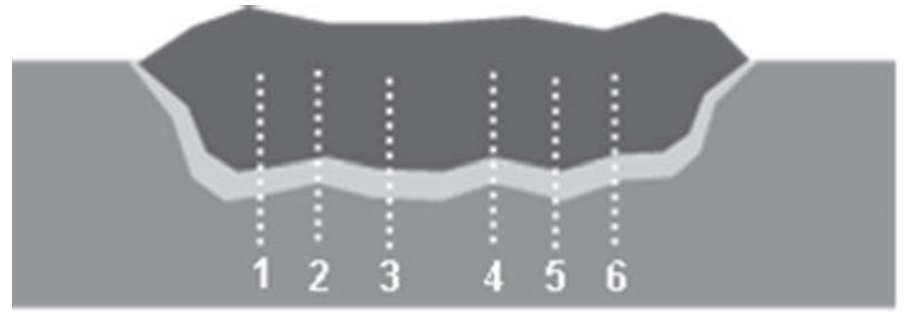

(a)

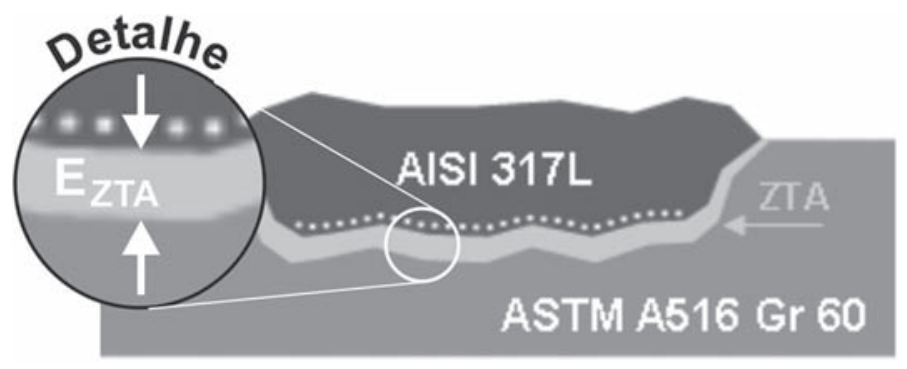

(b)

Figura 2 - Ensaio de microdureza (a) ao longo de linhas verticais com uma carga de $0,3 \mathrm{~kg}$ e (b) próxima à interface revestimento/substrato (carga: $0,1 \mathrm{~kg}$ ).

Tabela 4: Efeito dos parâmetros de soldagem na diluição e $\mathrm{E}_{\mathrm{ZTA}}$.

\begin{tabular}{cccccc}
\hline Ensaios & $\mathrm{I}(\mathrm{A})$ & $\begin{array}{c}\mathrm{V}_{\mathrm{s}} \\
(\mathrm{m} / \mathrm{min})\end{array}$ & $\mathrm{H}(\mathrm{kJ} / \mathrm{m})$ & $\begin{array}{c}\text { Diluição } \\
(\%)\end{array}$ & $\mathrm{E}_{\mathrm{ZTA}}(\mathrm{mm})$ \\
\hline 1 & 170 & 0,40 & 1530 & 12,88 & $2,01 \pm 0,20$ \\
2 & 130 & 0,40 & 1170 & 6,73 & $1,43 \pm 0,17$ \\
3 & 170 & 0,52 & 1170 & 8,25 & $1,48 \pm 0,16$ \\
\hline
\end{tabular}

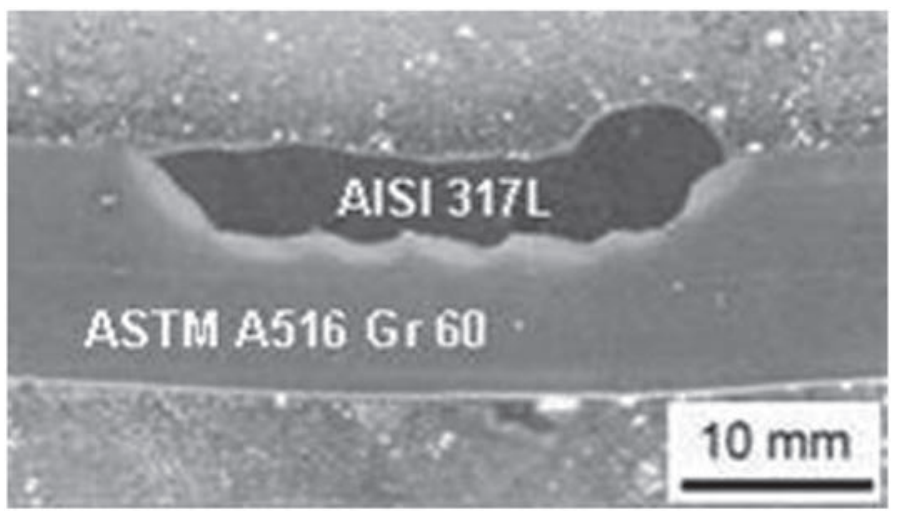

Figura 3 - Seção transversal do CP revestido.

A fim de facilitar a obtenção de espécimes para análises de propriedades mecânicas, optou-se por um corpo de prova - para o substrato - com um rasgo trapezoidal usinado a partir da sua superfície, conforme mostra a Figura 1a. A Figura 3 apresenta o resultado da aplicação do revestimento de aço AISI 317L neste substrato de aço ASTM A516 Gr 60 (Figura 4). Apesar de ser um tema de extrema relevância em SAD, a análise de propriedades mecânicas está fora do escopo do corrente trabalho. Este tema será abordado em trabalhos futuros. 


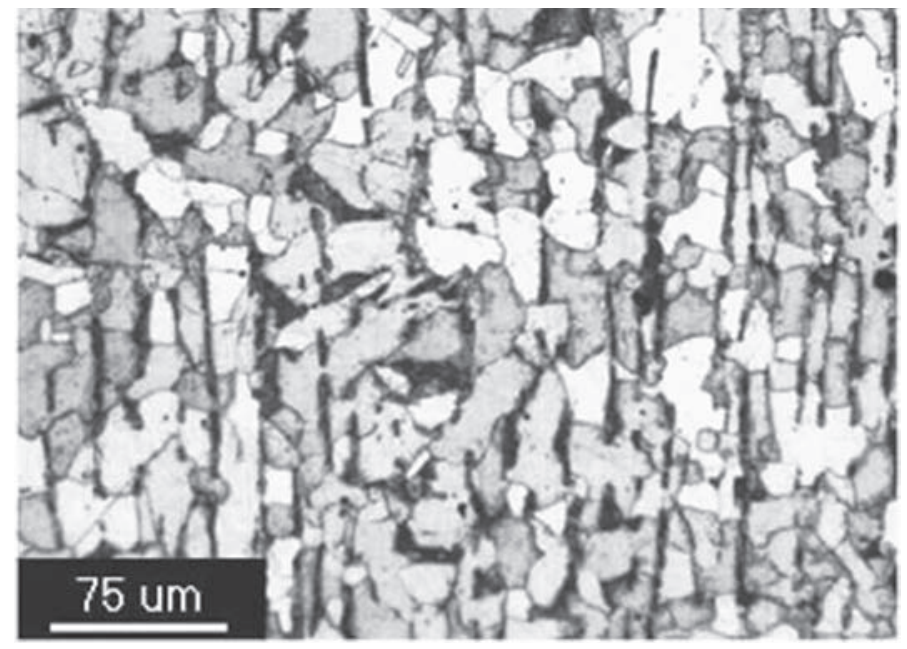

Figura 4 - Micrografia do substrato ASTM A516 Gr 60. Ataque: nital 1,5\%.

A Tabela 4 apresenta o efeito dos parâmetros de soldagem na diluição e na $\mathrm{E}_{\mathrm{ZTA}}$. A partir desta tabela e com um simples cálculo de média é possível obter uma $\mathrm{E}_{\mathrm{ZTA}}$ média igual a $1,45 \mathrm{~mm}$ para a energia de soldagem $(\mathrm{H})$ de $1170 \mathrm{~kJ} / \mathrm{mm}$. Assim, para um aumento de $360 \mathrm{~kJ} / \mathrm{m}$ na energia de soldagem, a $\mathrm{E}_{\text {ZTA }}$ aumentou aproximadamente $0,55 \mathrm{~mm}$. Entretanto, é necessário fazer ensaios mecânicos para analisar se este aumento de $0,55 \mathrm{~mm}$ implicou em mudanças significativas nas propriedades mecânicas da estrutura.

Ainda para $\mathrm{H}=1170 \mathrm{~kJ} / \mathrm{m}$, a diluição média foi de 7,49 $1,07 \%$, enquanto que para $\mathrm{H}=1530 \mathrm{~kJ} / \mathrm{m}$ a diluição foi de $12,88 \%$. Assim, pode-se afirmar que para um aumento de $360 \mathrm{~kJ} / \mathrm{m}$ na energia de soldagem a diluição aumentou aproximadamente 5,39\% (considerando a diluição média para $\mathrm{H}=1170 \mathrm{~kJ} / \mathrm{m}$ ).

$\mathrm{Na}$ Figura 5 observa-se a influência da corrente e da velocidade de soldagem sobre a diluição. Nota-se que é possível obter valores de diluições aproximadamente equivalentes para valores de correntes (I) diferentes desde que se alterem os valores de velocidade de soldagem $\left(\mathrm{v}_{\mathrm{s}}\right)$.

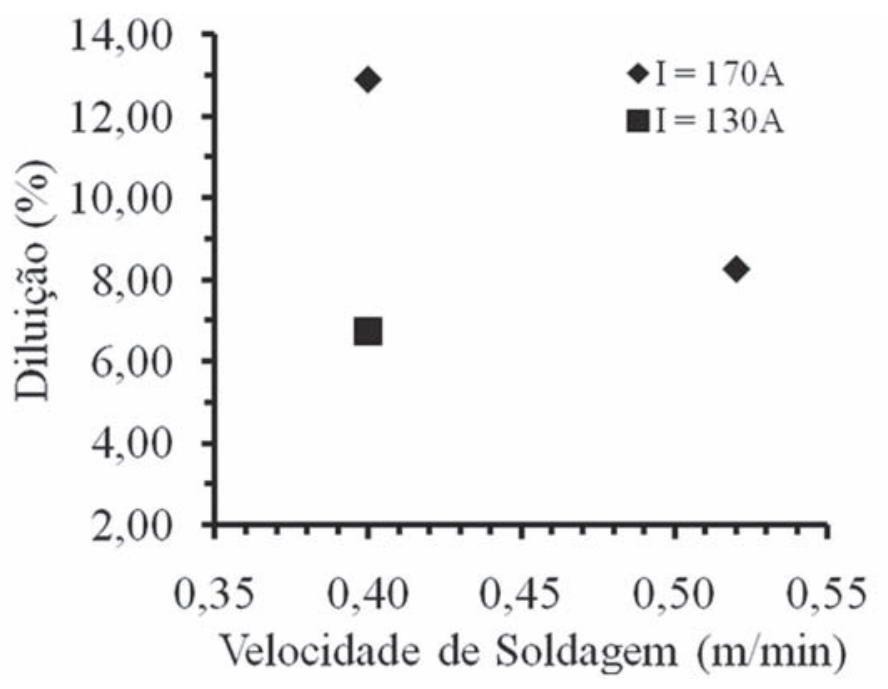

Figura 5 - Influência das velocidade e corrente de soldagem na diluição.
Observa-se que os menores valores de diluição foram obtidos para valores mais baixos de energia e corrente de soldagem e para velocidades de soldagem mais alta. Quanto maior for a diluição, maior será a participação de ferro e carbono no metal de solda. Assim, uma diluição reduzida é sempre desejada, pois além de minimizar a formação de microestruturas de alta temperabilidade e susceptíveis a ataque corrosivo, também contribui para evitar trincas de solidificação no MS $[6,14]$. Rowe et al. [15] melhoraram a resistência a trincas em revestimentos (para proteção contra corrosão) de aço inoxidável austenítico AISI 308 quando reduziram o nível de diluição de 40 pra $30 \%$.

Os resultados dos ensaios de microdureza realizados com uma carga de 0,3kg estão dispostos nas Figuras 6 e 7 (ensaios 1 e 2). Nestas figuras estão os valores de dureza para cada uma das seis linhas de impressões, conforme indica a Figura 2a.

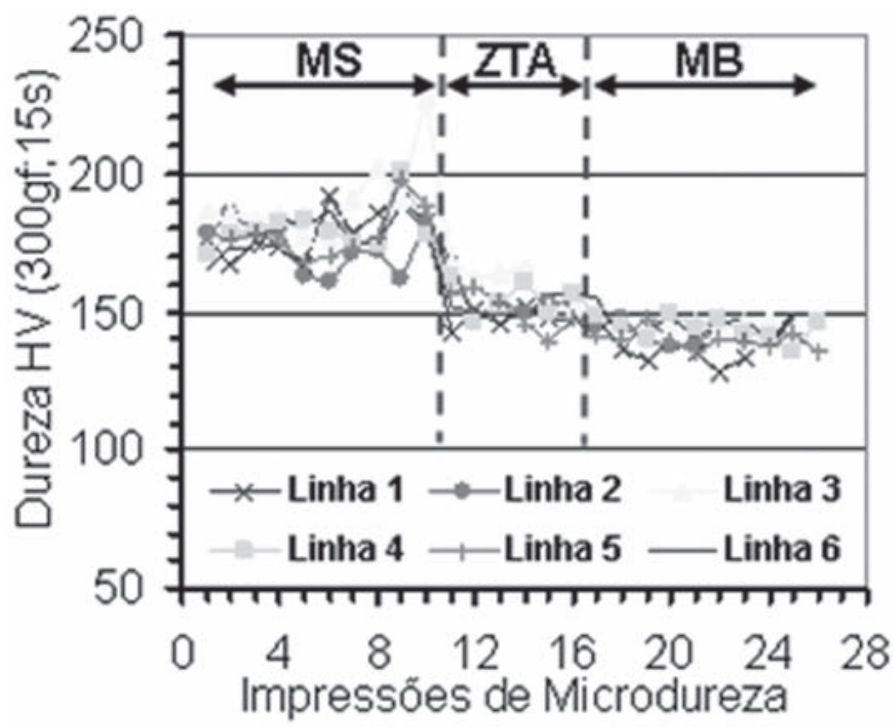

Figura 6 - Microdureza ao longo das linhas verticais para $\mathrm{H}=$ $1530 \mathrm{~kJ} / \mathrm{m}$. Ensaio 1.

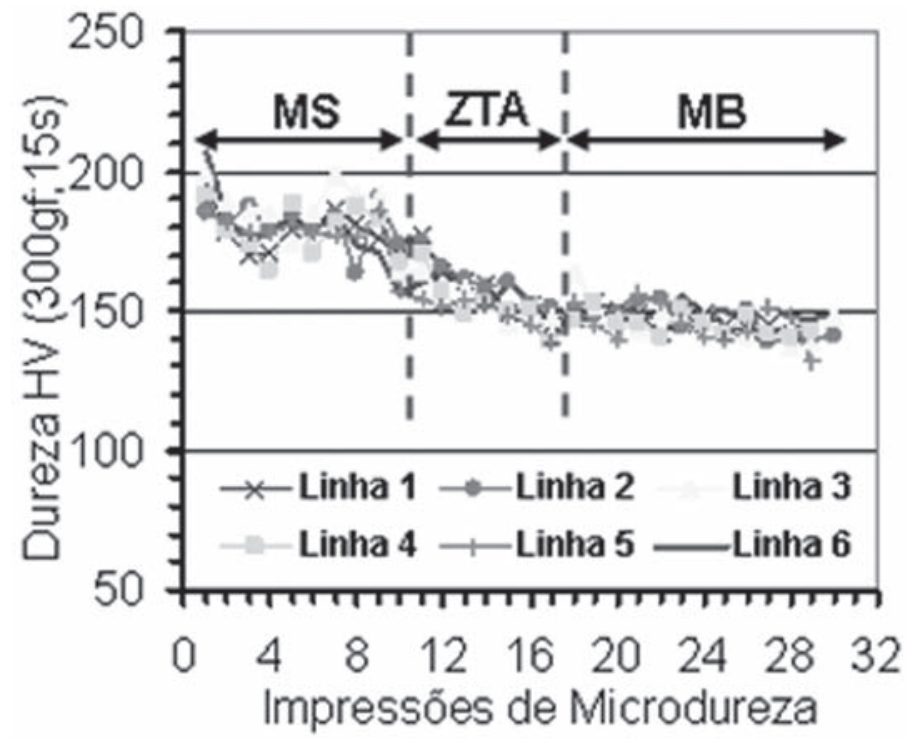

Figura 7 - Microdureza ao longo das linhas verticais para $\mathrm{H}=$ $1170 \mathrm{~kJ} / \mathrm{m}$. Ensaio 2. 
Os resultados do ensaio 3 foram análogos àqueles do ensaio 2, já que eles possuem o mesmo nível de energia de soldagem $(1170 \mathrm{~kJ} / \mathrm{m})$, embora possuam velocidade e corrente de soldagem diferentes. Os gradientes de dureza ao longo das regiões MS, ZTA e MB, podem ser verificados através das Figuras 6 e 7 para ambos os níveis de energia de soldagem. Verifica-se que o MS apresenta um nível de dureza mais alto, enquanto que a dureza da ZTA é levemente superior ao MB. Em termos de valores médios, para a $\mathrm{H}=1530 \mathrm{~kJ} / \mathrm{m}$ as durezas do MS e ZTA foram, respectivamente, $180,0 \mathrm{HV} \pm 9,0 \mathrm{HV}$ e $152,0 \pm 6,0 \mathrm{HV}$. E para $\mathrm{H}=1170 \mathrm{~kJ} / \mathrm{m}$, as durezas do MS e ZTA foram $182,0 \mathrm{HV} \pm 8,0$ $\mathrm{HV}$ e $158,0 \pm 7,0 \mathrm{HV}$, respectivamente. O MB apresentou uma dureza de $145,0 \pm 4,0 \mathrm{HV}$.

Embora não tenha sido uma variação significativa, o valor médio da dureza da ZTA para $\mathrm{H}=1170 \mathrm{~kJ} / \mathrm{m}$ foi $6 \mathrm{HV}$ maior que a dureza média da ZTA para $\mathrm{H}=1530 \mathrm{~kJ} / \mathrm{m}$. Apesar de energias de soldagem mais reduzidas resultar em taxas de resfriamento mais altas e, consequentemente, uma dureza mais elevada na ZTA de aços ferríticos, neste trabalho, quando se reduziu a energia de soldagem de $1530 \mathrm{~kJ} / \mathrm{m}$ para $1170 \mathrm{~kJ} / \mathrm{m}$ não foram observadas variações significativas de dureza ZTA. Kejelin et al. [6] obtiveram, para uma aço $1,15 \% \mathrm{Mn}$, um aumento de $20 \mathrm{HV}$ na dureza da ZTA quando eles reduziram a energia de soldagem de 1500 para $1100 \mathrm{~kJ} / \mathrm{m}$. No entanto, a espessura do tubo - sobre o qual foi depositado o cordão de solda - foi de $20 \mathrm{~mm}$. Já no corrente trabalho a espessura do substrato foi de $12,7 \mathrm{~mm}$ e, após a usinagem do canal no centro do corpo de prova, a nova espessura do substrato passou a ser $8,7 \mathrm{~mm}$ (Figura 1a). Este fato pode explicar a pequena variação na taxa de resfriamento e, consequentemente, nos níveis de dureza da ZTA.

As Figuras 8 e 9 mostram os valores de dureza ao longo da interface revestimento/substrato para valores de energia de soldagem de $1530 \mathrm{~kJ} / \mathrm{m}$ e $1170 \mathrm{~kJ} / \mathrm{m}$, respectivamente. Estes resultados são oriundos daquele ensaio de microdureza realizado com uma carga de $0,1 \mathrm{~kg}$ com as impressões dispostas ao longo da interface de acordo com a Figura 2b. Utilizou-se esta carga porque essas regiões (interface) podem conter ZPD, que são zonas estreitas, e a impressão - correspondente a uma carga elevada - pode ser maior do que a largura da mesma e, portanto, poderá não refletir a verdadeira dureza da região.

Assim, analisando-se as Figuras 8 e 9, constata-se que para $\mathrm{H}=1530 \mathrm{~kJ} / \mathrm{m}$ - quando comparado com $\mathrm{H}=1170 \mathrm{~kJ} / \mathrm{m}$ - ocorreram mais pontos que apresentaram valores de dureza acima de $250 \mathrm{HV}$, que é o limite estabelecido pela NACE para metais de base de aços carbonos, inoxidáveis e metais de solda utilizados em meios úmidos sulfurosos [1,2].

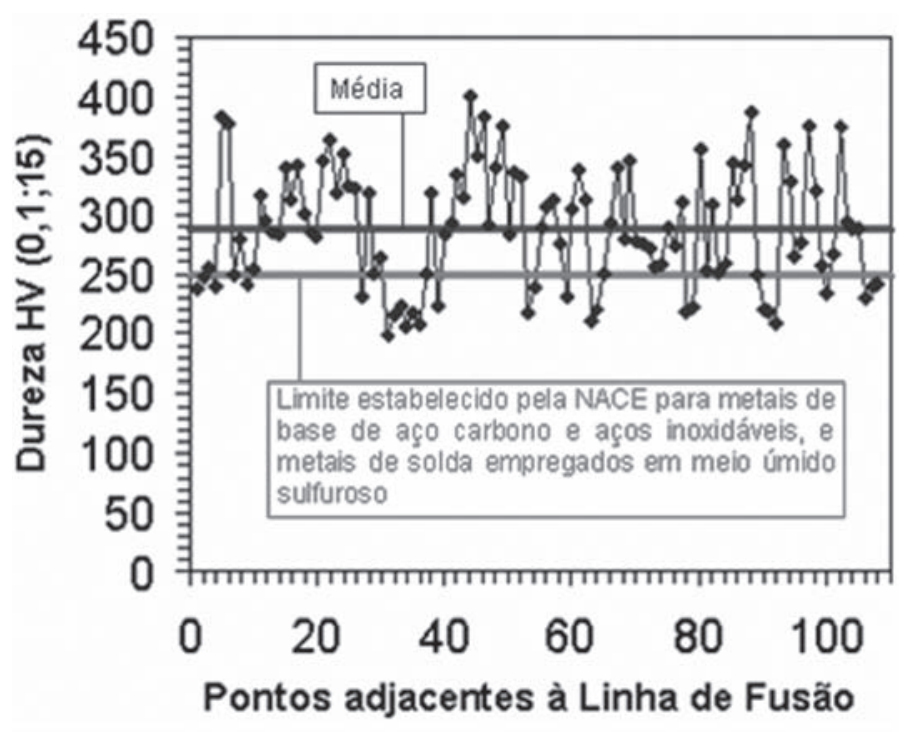

Figura 8 - Gradiente de dureza ao longo da interface revestimento/substrato para 1530kJ/m. Diluição: 12,88\%.

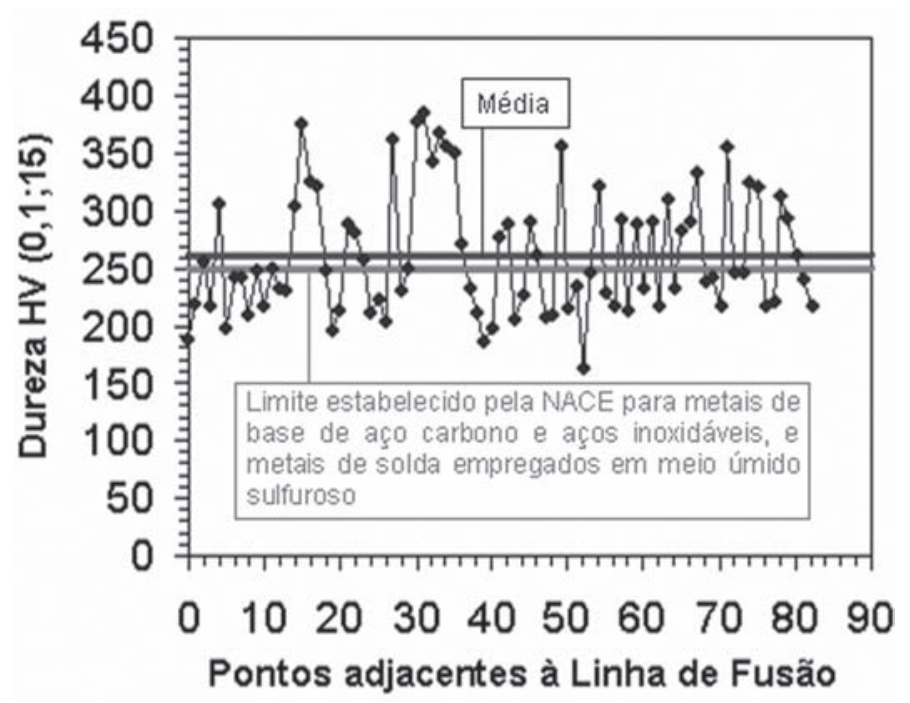

Figura 9 - Gradiente de dureza ao longo da interface revestimento/substrato para $1170 \mathrm{~kJ} / \mathrm{m}$. Diluição: 6,73\%.

Tabela 5: Comparativos entre os níveis de dureza ao longo da LF para H=1530kJ/m e H=1170kJ/m.

\section{IMPRESSÕES ADJACENTES À LINHA DE FUSÃO (LF)}

\begin{tabular}{|c|c|c|c|c|}
\hline \multirow{2}{*}{ NÍVEL DE DUREZA } & \multicolumn{2}{|c|}{$\mathrm{H}=1530 \mathrm{~kJ} / \mathrm{m}$} & \multicolumn{2}{|c|}{$\mathrm{H}=1170 \mathrm{~kJ} / \mathrm{m}$} \\
\hline & $\mathrm{N}^{\circ}$ de Impress. & Percentual & $\mathrm{N}^{\mathrm{o}}$ de impress. & Percentual \\
\hline Dureza acima de $200 \mathrm{HV}$ & 107 & $99,07 \%$ & 77 & $92,77 \%$ \\
\hline Dureza acima de $250 \mathrm{HV}^{*}$ & 80 & $74,07 \%$ & 27 & $32,53 \%$ \\
\hline Dureza acima de $300 \mathrm{HV}$ & 43 & $39,81 \%$ & 20 & $24,10 \%$ \\
\hline Dureza acima de $350 \mathrm{HV}$ & 13 & $12,04 \%$ & 8 & $9,64 \%$ \\
\hline Dureza acima de $400 \mathrm{HV}$ & 1 & $0,93 \%$ & 0 & $0,00 \%$ \\
\hline Total de impressões & \multicolumn{2}{|c|}{108} & \multicolumn{2}{|c|}{83} \\
\hline
\end{tabular}


Outra maneira de avaliar estes resultados é comparar a média de todas as medidas com este limite estabelecido pela NACE (250HV). O valor médio das medidas foi $287,57 \pm 49,81 \mathrm{HV}$ para $\mathrm{H}=1530 \mathrm{~kJ} / \mathrm{m}$ e $261,7 \pm 53,3 \mathrm{HV}$ para $\mathrm{H}=1170 \mathrm{~kJ} / \mathrm{m}$. Estes valores médios também podem ser verificados nas Figuras 8 e 9 .

A Tabela 5 expõe de forma comparativa os resultados do ensaio de microdureza ao longo da linha de fusão para as energias de soldagem de $1530 \mathrm{~kJ} / \mathrm{m}$ e $1170 \mathrm{~kJ} / \mathrm{m}$. Observa-se que $74,07 \%$ das impressões apresentaram valores de dureza acima do limite estabelecido pela NACE, para $\mathrm{H}=1530 \mathrm{~kJ} / \mathrm{m}$. Ao comparar estes resultados com aqueles obtidos para $\mathrm{H}=1170 \mathrm{~kJ} / \mathrm{m}$, notase uma redução significativa de impressões que exibiram um valor de dureza acima do limite da NACE, isto é, 32,53\% das impressões apresentaram valores acima de $250 \mathrm{HV}$ quando se reduziu a energia para $1170 \mathrm{~kJ} / \mathrm{m}$. Este resultado está coerente com aqueles obtidos para a diluição, já que esta energia de $1170 \mathrm{~kJ} / \mathrm{m}$ proporcionou valores menores para a diluição e, consequentemente, reduzindo a quantidade de zonas com dureza elevada.

Investigando a interface revestimento/substrato verificase que estes valores de dureza elevada - para ambos os níveis de energia de soldagem - são devidos à presença de regiões localizadas que apresentam zonas frágeis, ou seja, ZPD de diferentes morfologias. E são nos contornos, ou dentro, destas ZPD que se encontram locais de dureza elevada.

A Figura 10 mostra a presença de uma ZPD com uma morfologia de banda estreita (praia) ao longo da linha de fusão, do lado do metal de solda. Esta é regiao é confirmada através das impressões de dureza que apresentam valores acima de 260,0HV. Verifica-se que, ainda dentro do MS e imediatamente fora desta zona estreita a dureza se reduz para 196,8HV.

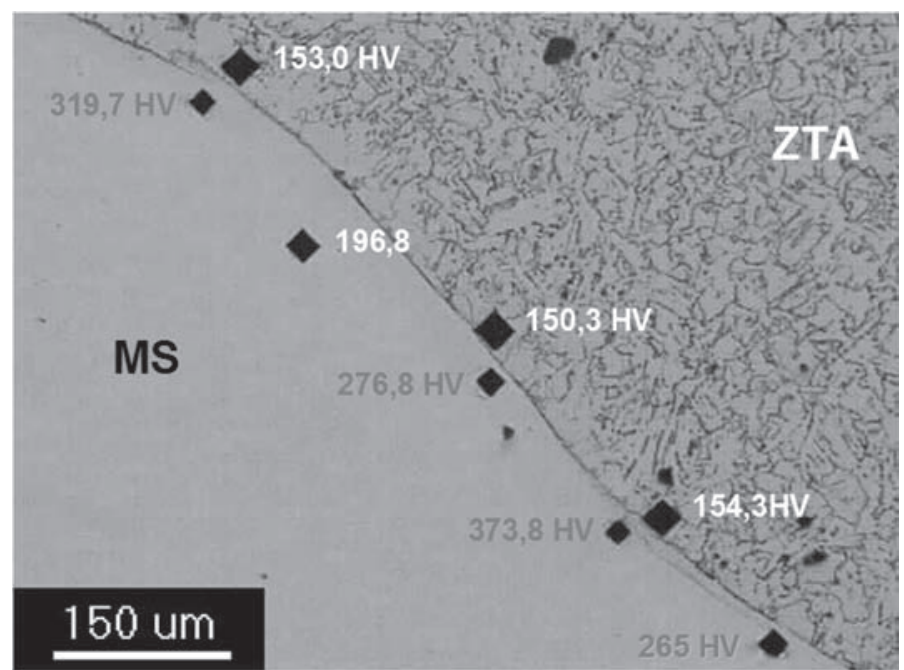

Figura 10 - Medidas de dureza confirmando a presença de uma ZPD. $\mathrm{H}=1530 \mathrm{~kJ} / \mathrm{m}$. Diluição: 10,72\%. Amp.: 100x. Nital $(1,5 \%)$, por 20 s.

Já a Figura 11 apresenta a mesma região da Figura 10, com alteraração do foco no microscópio a fim de evidenciar a estreita faixa desta zona, que apresentou uma largura de aproximadamente $34 \mathrm{~mm}$.

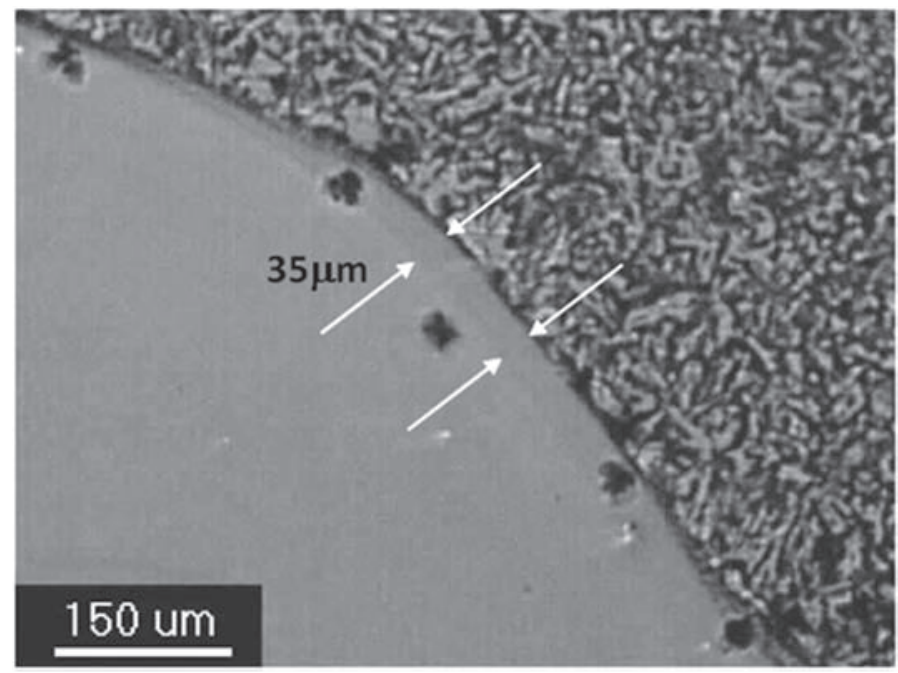

Figura 11 - A mesma região da figura 10 com o foco alterado buscando ênfase à estreita faixa de dureza elevada (ZPD). Amp.: 100x.

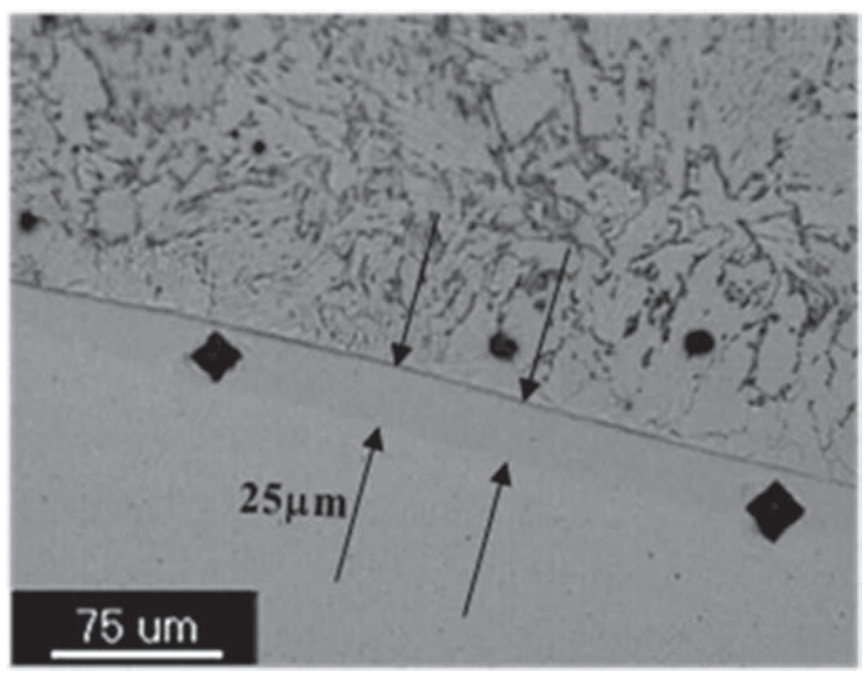

Figura 12 - Medidas de dureza confirmando a presença de uma ZPD (praia). H=1170kJ/m. Diluição: 6,73\%. Amp.: 200x. Nital $(1,5 \%)$, por $20 \mathrm{~s}$.

Verificou-se também que ZPD com a moforlogia das Figuras 10, 11 e 12 ocorreram tanto para $\mathrm{H}=1530 \mathrm{~kJ} / \mathrm{m}$ (diluição de $10,72 \%$ ) quanto para $\mathrm{H}=1770 \mathrm{~kJ} / \mathrm{m}$ (diluição de $6,73 \%$ ), entretanto, para a energia de soldagem maior a largura destas ZPD foram maiores ( $35 \mu \mathrm{m}$, Figura 11) enquanto que a energia de $1170 \mathrm{~kJ} / \mathrm{m}$ proporcionou larguras menores (25 $\mu \mathrm{m}$, Figura 12 ).

A Figura 13 mostra uma outra morfologia de ZPD, isto é, uma região do MS parcialmente rodeada pelo MB (península) para $\mathrm{H}=1530 \mathrm{~kJ} / \mathrm{m}$. Foi constatado também que para a energia de soldagem maior o tamanho destas ZPD foram maiores, bem como o espaçamento entre as partes do MS (30 $\mu \mathrm{m}$, Figura 13), quando comparado com o nível de energia de soldagem menor (Figura 14). 


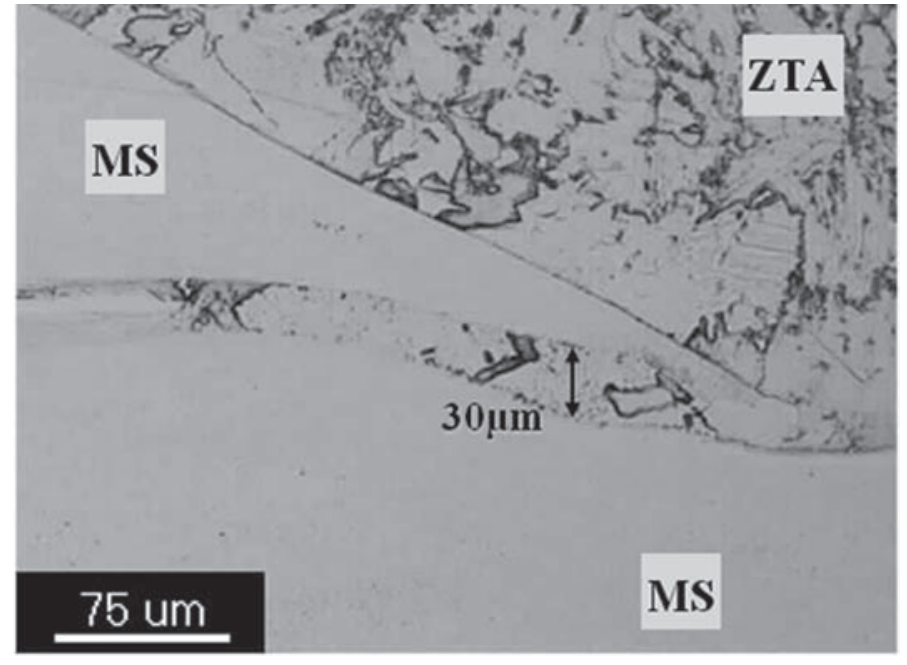

Figura 13 - ZPD com morfologia de um península para H=1530kJ/m. Diluição: 10,72\%. Amp.: 200x. Nital (1,5\%), por 20 s.

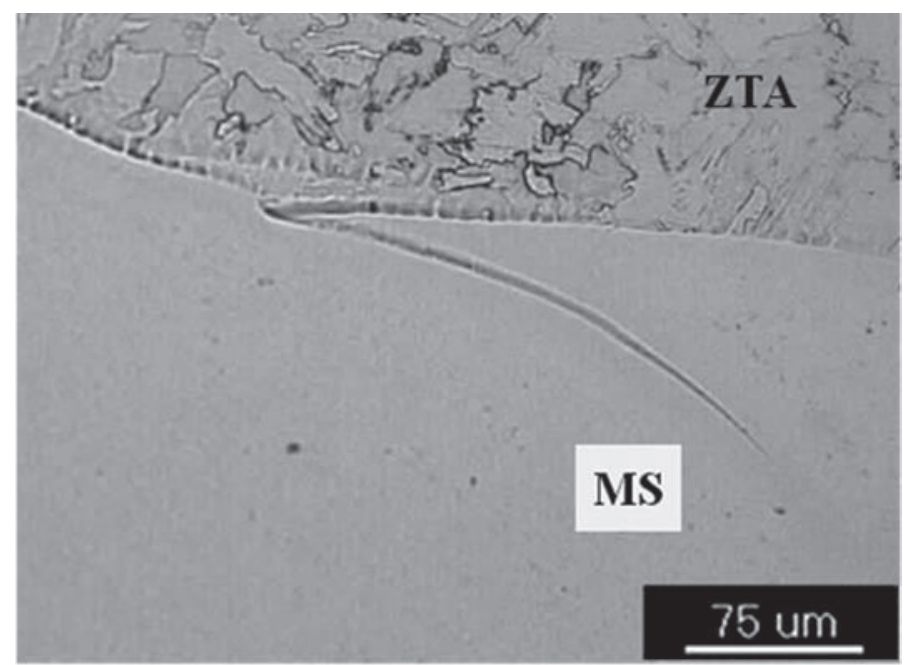

Figura 14 - ZPD com morfologia de uma pensínsula para $\mathrm{H}=1170 \mathrm{~kJ} / \mathrm{m}$. Diluição: 6,73\%. Amp.: 200x.

A Figura 15 apresenta uma outra heterogeneidade (ZPD) que pode ocorrer próximo à interface da solda, isto é, porções do MB (ilhas) totalmente cercadas pelo MS. Estas ZPD não foram identificadas nas interfaces de solda obtidas com $\mathrm{H}=1170 \mathrm{~kJ} / \mathrm{m}$. Além disso, quantidade desta morfologia (para $\mathrm{H}=1530 \mathrm{~kJ} / \mathrm{m}$ ) foram bem menores do que as outras (Figuras 10 e 13).

Após a análise através de metalografia com o reagente químico Nital (1,5\%) por 20s, utilizou-se este mesmo reagente, porém com um tempo de ataque de 180s (3 minutos). Daí, verificou-se que houve zonas de dureza elevada que não foram sensíveis ao ataque, conforme mostra a Figura 16, e outras que foram sensíveis ao ataque (Figura 17). As Figuras 18 e 19 apresentam a ZPD da Figura 17 em aumentos de 500 e 1000x, respectivamente.

Nota-se, portanto, que a ZPD que foi sensível ao ataque apresentou uma estrutura acicular, confirmando a presença de martensita, podendo conter também traços de bainíta. Ainda na Figura 17, observa-se a existência de uma ZPD de até $48 \mathrm{~mm}$ de largura.

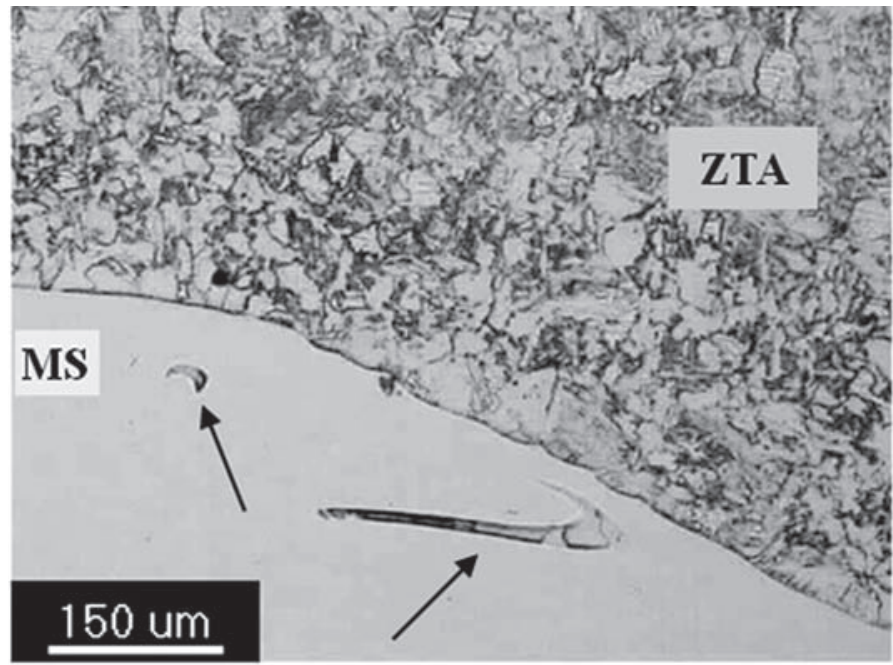

Figura 15 - ZPD (porções do MB cercadas pelo MS). $\mathrm{H}=1530 \mathrm{~kJ} / \mathrm{m}$. Diluição: 10,72\%. Amp.:100x. Nital (1,5\%), por 20 s.

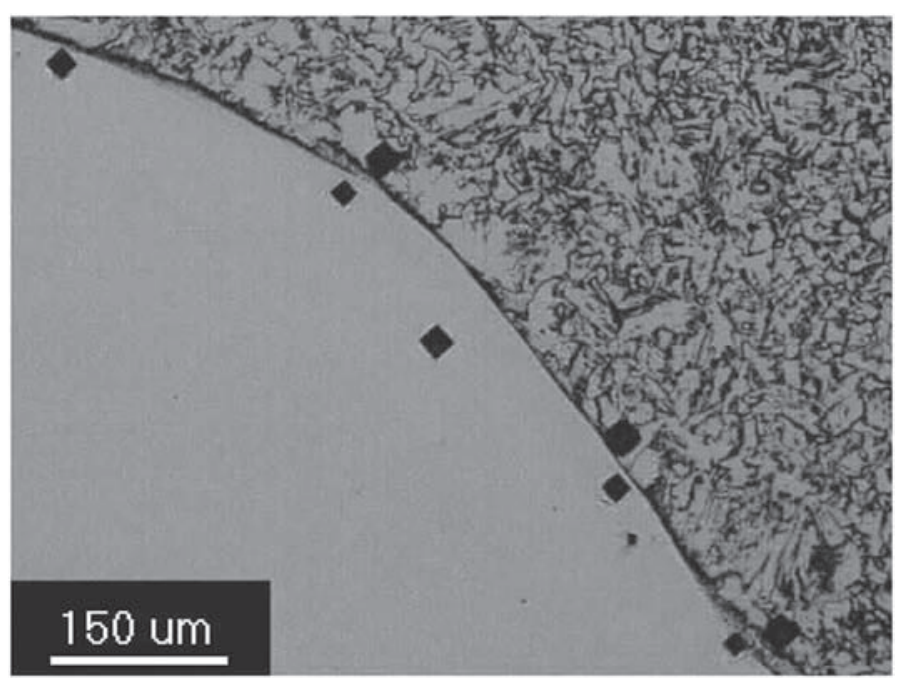

Figura 16 - ZPD indiferente ao ataque nital (1,5\%) por 3 minutos. $\mathrm{H}=1530 \mathrm{~kJ} / \mathrm{m}$. Diluição: 10,72\%. Amp.: 100x.

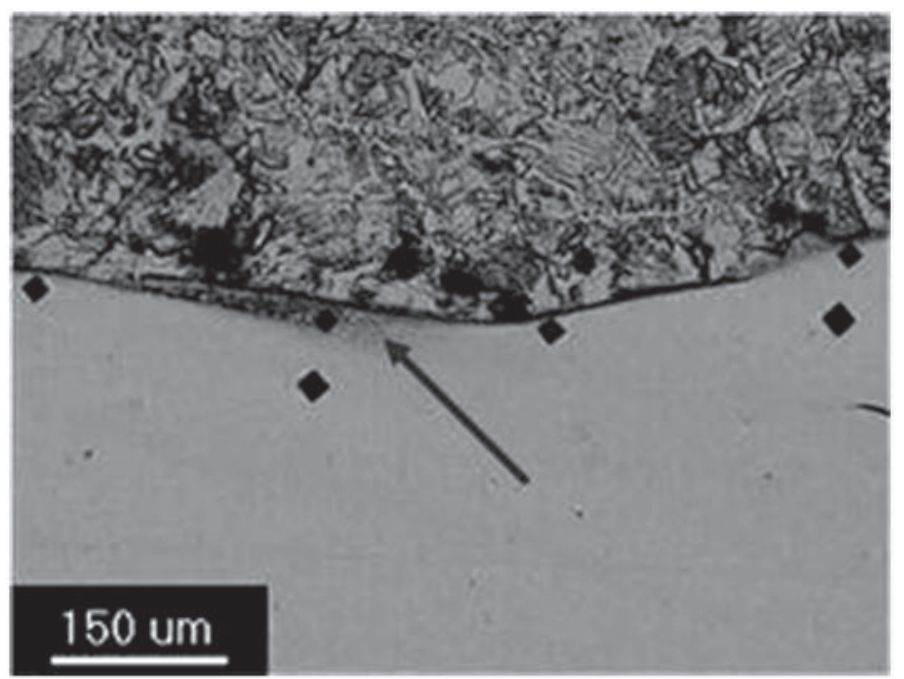

Figura 17 - ZPD sensível ao ataque nital (1,5\%) por 3 minutos. $\mathrm{H}=1530 \mathrm{~kJ} / \mathrm{m}$. Diluição: 10,72\%. Amp.: 100x. 


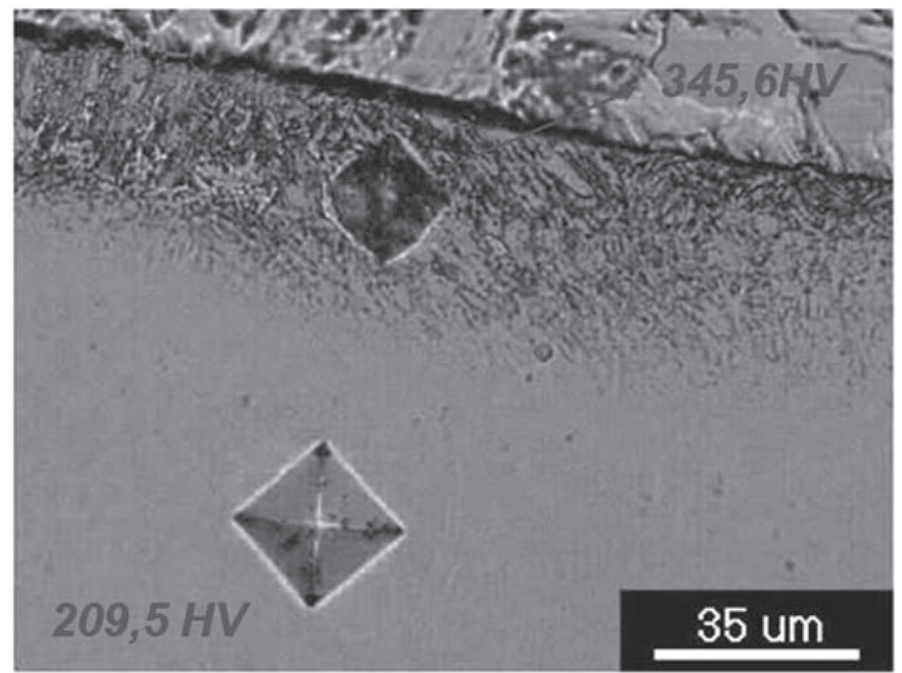

Figura 18 - Microestrutura da ZPD da Figura 17. Ampliação: 500x.

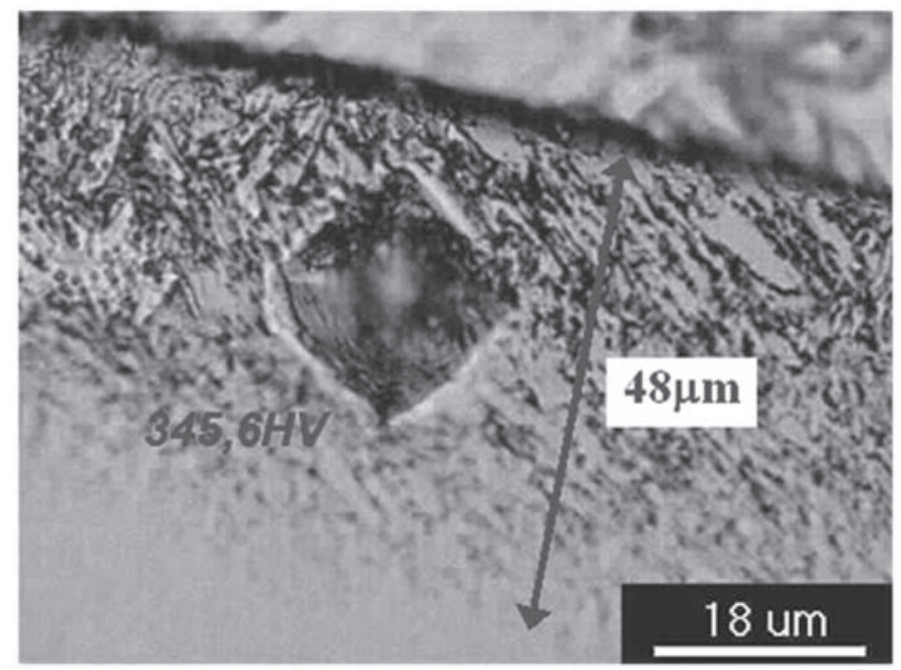

Figura 19 - Microestrutura da ZPD da Figura 17. Ampliação: 1000x. Nital (1,5\%), por 3 minutos.

Devido à diferença significativa entre as composições químicas do MB (aço C-Mn) e o metal de adição (aço inoxidável) ocorre migração de carbono do MB para o MS durante a soldagem. $\mathrm{O}$ alto conteúdo de $\mathrm{Cr}$ no MS proporciona a difusão de $\mathrm{C}$ do aço carbono para o MS austenítico [2]. Além disso, a composição de baixa liga (por exemplo, 3-5\% Cr e $2-3 \% \mathrm{Ni}$ ) das ZPD é o fator determinante para promover a formação de martensita e, quanto maior a quantidade de $\mathrm{C}$ difundida, maior será a dureza da ZPD [2, 16].

No entanto, parece existir no mínimo dois tipos microestruturas - ou uma mistura delas - nestas ZPD. Conforme pode ser verificado nas Figuras 16 e 18, a primeira não foi sensível ao ataque, já a segunda teve sua microestrutura revelada. $\mathrm{O}$ certo é que ambas apresentaram valores de dureza acima de $300 \mathrm{HV}$. De acordo com a literatura as ZPD também podem conter precipitados ou intermetálicos formados durante a soldagem [1,17]. Omar [1] afirma que dependendo da taxa de resfriamento do MS, podem existir dois tipos de microestrutura na ZPD responsáveis pelo os altos valores de dureza nas mesmas. Se a taxa for alta uma microestrutura predominantemente martensítica se forma na ZPD. Por outro lado, se a taxa for muito lenta a ZPD é constituída predominantemente por precipitados. Esta segunda situação pode justificar a diferença de microestrutura entre as Figuras 16 e 18 e, consequentemente, o porquê da microestrutura da Figura 16 não ter sido sensível ao ataque Nital $(1,5 \% ; 3 \mathrm{~min})$.

Outra característica destas ZPD é que elas são localizadas e não contínuas ao longo da interface. A Figura 20 apresenta uma região da interface com ausência de ZPD.

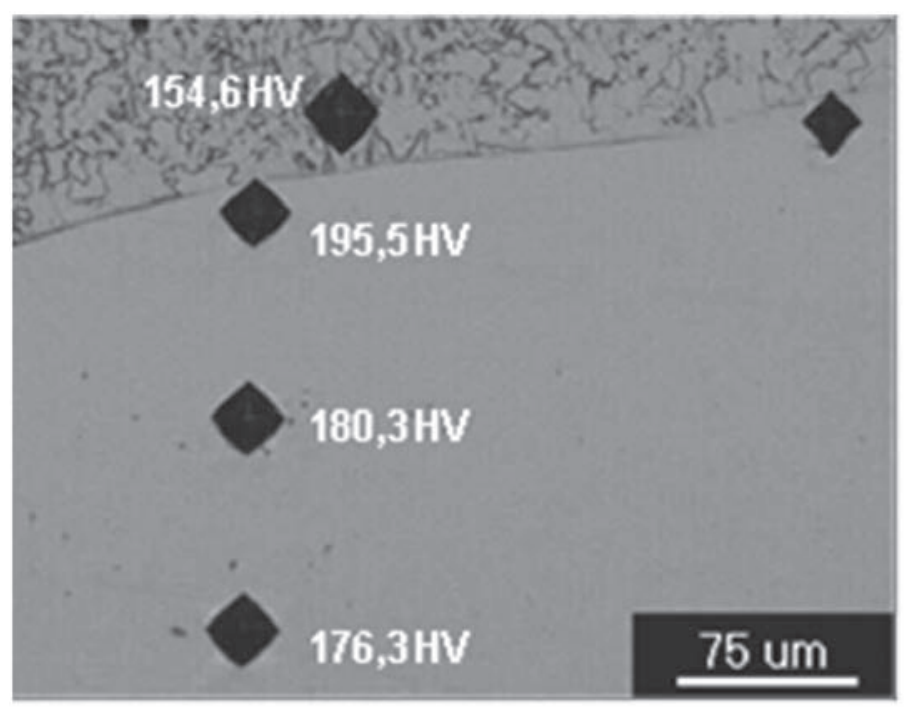

Figura 20 - Ausência de ZPD. H=1170kJ/m. Diluição: 6,73\%. Nital $(1,5 \%)$.

As regiões da interface revestimento/substrato onde não ocorrem ZPD pode estar associado ao arrastamento, por convecção, daquela camada de MB líqudo na interface da poça de fusão. As forças motrizes que contribuem para esta convecção incluem: força eletromagnética, gradientes de tensões superficiais, jateamento de gotículas de metal de adição e cisalhamento do arco elétrico (induzido pelo jato de plasma do arco). Assim, a convecção da poça da solda pode torna-se turbulenta e instável [10, 18].

Os parâmetros de soldagem utilizados no corrente trabalho não provocaram a eliminação da ZPD na interface revestimento/ substrato, porém o nível de energia de soldagem menor $(\mathrm{H}=1170 \mathrm{~kJ} / \mathrm{m})$ proporcionou uma redução significativa na quantidade das ZPD nesta interface. Isto pode ser comprovado através dos resultados dos testes de microdureza, conforme mostra as Figuras 8 e 9, e a Tabela 5, já que os altos valores de dureza estão associados com a presença de ZPD.

As ZPD são fenômenos metalúrgicos indesejáveis durante uma SAD, pois são regiões susceptíveis à corrosão localizada ("pitting"), fragilização por hidrogênio e corrosão sob tensão $[1,2,15,17]$. Apesar de ocorrer uma redução significativa na formação da ZPD quando se reduziu de $360 \mathrm{~kJ} / \mathrm{m}$ a energia de soldagem, em atividades futuras serão alterados outros parâmetros de soldagem a fim de minimizar ainda mais ou até eliminar a ocorrência destas zonas. Segundo a literatura, 
os parâmetros de maior influência na formação de ZPD são as composições químicas dos metais de adição e de base juntamente com a taxa de resfriamento na soldagem [1]. Por sua vez, a taxa de resfriamento não só é influenciada pela energia de soldagem, como também pela temperatura de pré-aquecimento e espessura do substrato. Já com relação ao tratamento térmico após a soldagem, parece ser unânime entre os pesquisadores que o mesmo apresenta um efeito negativo nas propriedades mecânicas da estrutura. As principais causas deste efeito negativo são: a migração de carbono do MB para o MS e a conseqüente perda de resistência mecânica da região empobrecida em carbono $[1,14,17]$.

\section{4 - Conclusão}

Uma análise da aplicação de revestimentos de aço AISI 317L em substratos de aço ASTM A516 Gr 60, através do processo de soldagem GMAW com duplo arame e para diferentes níveis de energia de soldagem, foi apresentado. Constatou-se que a extensão da ZTA, a diluição e quantidade (e tamanho) das ZPD diminuíram com redução da energia de soldagem. Para uma redução de $360 \mathrm{~kJ} / \mathrm{m}$ na energia de soldagem, ocorreram reduções de $0,55 \mathrm{~mm}$ na extensão da ZTA e de 5,39\% na diluição. Para $\mathrm{H}=$ $1170 \mathrm{~kJ} / \mathrm{m}, 32,53 \%$ das impressões de microdureza na interface revestimento/substrato apresentaram valores de dureza acima de $250 \mathrm{HV}$. Já para $\mathrm{H}=1530 \mathrm{~kJ} / \mathrm{m}$ este percentual subiu para $74,07 \%$. Entretanto, apesar destas reduções, ainda ocorreram pontos de dureza acima de $300 \mathrm{HV}$ para ambos os níveis de energia de soldagem, devido ao fato das ZPD, que contêm microestruturas frágeis e susceptíveis a ataques corrosivos, não terem sido eliminadas completamente. Torna-se, portanto, necessário variar outros parâmetros de soldagem a fim de reduzir ainda mais ou eliminar estas zonas.

\section{5 - Agradecimentos}

Os autores agradecem a Agência Nacional de Petróleo, Gás Natural e Biocombustíveis (ANP), a Rede Multitarefas de Materiais Avançados do Norte e Nordeste (REMULT) através do Núcleo de União e Revestimentos de Materiais (UNIREV), a FINEP e ao CNPq.

\section{REFERÊNCIAS BIBLIOGRÁFICAS}

[1] OMAR, A. A.. Effects of Welding Parameters on Hard Zones Formation at Dissimilar Metal Welds. Welding Journal, Miami, v. 77, n. 2, p.86-93, Feb. 1998.

[2] DOODY, T.. Intermediate Mixed Zones in Dissimilar Metal Welds for Sour Service. Welding Journal, v. 71, n. 3, pgs. 55-60, March 1992.

[3] AVERY, Richard E.. Pay attention to dissimilar-metal welds. Chemical Engineering Progress, New York, v. 87, n. 5, p.70-75, May 1991.

[4] ZEEMANN, A.. Diluição. Disponível em: <http://www. infosolda.com.br/download/50dda.pdf $>$. Acesso em: 26 maio 2008.

[5] MISSORI, S.; KOERBER, C.. Laser Beam Welding of
Austenitic-Ferritic Transition Joints. Welding Journal, Miami, v. 76, n. 3, p.125-134, March 1997

[6] KEJELIN, N. Z.; BUSCHINELLI, A. J. A.; BOHÓRQUEZ, C. E. N.. Soldagem Dissimilar do Aço X-60 com Inconel 625. Disponível em: <http://www.labsolda.ufsc.br/noticias/2007/ soldagem_dissimilar.pdf $>$. Acesso em: 02 fev. 2008.

[7] PARANHOS, R.. Revestimento de Aço Carbono com Aço Inoxidável Austenítico. Disponível em: <http://www.infosolda. com.br/download/12ddc.pdf $>$. Acesso em: 26 maio 2008.

[8] WAINER, E.; BRANDI, S. Duarte.; MELLO, Fábio. D. H.. SOLDAGEM: Processos e Metalurgia. São Paulo: Edgard Blücher Ltda, 1992.

[9] FOX, R. W; MCDONALD, A.T.. Introdução à Mecânica dos Fluidos. Editora Guanabara Koogan S.A., 1995. 662p.

[10] KOU, S.; YANG, K.. Fusion-Boundary Macrosegregation in Dissimilar-Filler Welds. Welding Journal, Miami, v. 86, n. 10, Oct. 2007.

[11] SAVAGE, W. F., NIPPES, E. F., SZEKERES, E. S.. A study of fusion boundary phenomena in low alloy steel. Welding Journal, Miami, v. 55, n. 9, Sept. 1976.

[12] AMERICAN SOCIETY FOR TESTING AND MATERIALS (ASTM). A516/516M: Standard Specification for Pressure Vessel Plates, Carbon Steel, for Moderate - and LowerTemperature Service. United States, 2004. 3 p.

[13] BÖHLER WELDING GROUP. Aceros Inoxidables. Disponível em: <http://www.bohlerweldinggroup.com.ar/ spanish/50_ESN_HTML.htm>. Acesso em: 27 out. 2008.

[14] LIPPOLD, John C.; KOTECKI, Damian J.. Welding Metallurgy and Weldability of Stainless Steels. Hoboken: Wiley Intercience, 2005. $357 \mathrm{p}$.

[15] ROWE, D.; NELSON, T. W.; LIPPOLD, J. C.. HydrogenInduced Cracking Along the Fusion Boundary of Dissimilar Welds. Welding Journal, Miami, v. 78, n. 2, p.31-37, Feb. 1999.

[16] WANG, Zhihui; XU, Biyu; YE, Ciqi. Study of the Martensite Structure at the Weld Interface and the Fracture Toughness of Dissimilar Metals Joints. Welding Journal, Miami, v. 72, n. 8, p.397-402, Aug. 1993.

[17] LUNDIN, C. D.. Dissimilar Metal Welds: Transition Joints Literature Review. Welding Journal, Miami, v. 61, n. 2, p.58-63, Feb. 1982.

[18] KOU, S. Welding Metallurgy. 2 ed. New York: Jonh Wiley \& Sons, Inc. 2003. 461p. 